\title{
High efficient white light emission of rare earth-free $\mathrm{MnO}-\mathrm{SnO}-\mathrm{ZnO}-\mathrm{P}_{2} \mathrm{O}_{5}$ glass
}

\author{
Hirokazu MASAI, ${ }^{\dagger}$ Takumi FUJIWARA, ${ }^{*}$ Syuji MATSUMOTO, ${ }^{* *}$ Yoshihiro TAKAHASHI, \\ Kenichiro IWASAKI, ${ }^{*}$ Yomei TOKUDA and Toshinobu YOKO \\ Institute for Chemical Research, Kyoto University, Gokasyo, Uji, Kyoto 611-0011 \\ * Department of Applied Physics, School of Engineering, Tohoku University, 6-6-05 Aoba, Sendai 980-8579 \\ ${ }^{* *}$ Research Center, Asahi Glass Co. Ltd., 1150 Hazawa-cho, Kanagawa-ku, Yokohama 211-8755
}

\begin{abstract}
White light emission of rare earth (RE)-free Mn-doped $\mathrm{SnO}-\mathrm{ZnO}-\mathrm{P}_{2} \mathrm{O}_{5}$ glass is demonstrated. Glass transition temperature of the obtained glass is below $440^{\circ} \mathrm{C}$, which assures the application to sealant of solid state light emitting devices. The RE-free transparent glass shows white light emission with a high value of quantum efficiency (QE) comparable to conventional crystalline phosphor by excitation of deep UV light. The broad emission of RE-free transparent glass can be continuously tuned by both the amount of activator and the composition of the glass without decrease of the QE value.
\end{abstract}

(2011 The Ceramic Society of Japan. All rights reserved.

Key-words : Glass, Emission, Sn, Phosphor, Rare earth-free

[Received July 7, 2011; Accepted August 8, 2011]

\section{Introduction}

Rare earth (RE)-containing materials have been widely used in our daily life. For example, optical materials containing trivalent $\mathrm{RE}$ cations such as $\mathrm{Y}_{3} \mathrm{Al}_{5} \mathrm{O}_{12}: \mathrm{Nd}^{3+}$ or $\mathrm{Er}^{3+}$-doped fiber amplifier are typical fundamental optical materials. These trivalent $\mathrm{RE}$ cations show narrow band emission in the visible or IR region, which is brought by the $4 \mathrm{f}-4 \mathrm{f}$ transition that is hardly affected by the surrounding crystal field. Recently, the strong, sharp emission of RE-cation has been also used for white-light-emitting devices. One application is the three narrow emission band type fluorescent lamp (the so-called three-band lamp) consisting of RE-doped blue, red, and green phosphors. ${ }^{1)}$ Another application is the white light-emitting diode (LED) that basically consists of blue-LED and commercially available yellow phosphor such as $\mathrm{Y}_{3} \mathrm{Al}_{5} \mathrm{O}_{12}: \mathrm{Ce}^{3+}{ }^{1}$.) However, these white-emitting devices consisting of sharp emission bands possess lower color rendering than the conventional broad band emission device. Since there is uncertainty about the stable supply of RE over the future, RE-free material have been enthusiastically examined.

We have focused on the RE-free phosphors that have been used for white fluorescent lamp. Since white light emission was composed of various kinds of wavelengths, it is expected that white light emission can be attained by RE-free phosphor, for example $\mathrm{Sb}^{3+}, \mathrm{Mn}^{2+}$-doped calcium halophosphate, $\left[\mathrm{Ca}_{5}\left(\mathrm{PO}_{4}\right)_{3}(\mathrm{~F}, \mathrm{Cl}): \mathrm{Sb}^{3+}, \mathrm{Mn}^{2+}\right]{ }^{2)}$ Although the emission of the $\mathrm{Sb}^{3+}, \mathrm{Mn}^{2+}$-doped calcium halophosphate generally possesses two broad emission bands at $480 \mathrm{~nm}\left(\mathrm{Sb}^{3+}\right)$ with a half width at half-maximum (HWHM) of $140 \mathrm{~nm}$, and at $580 \mathrm{~nm}\left(\mathrm{Mn}^{2+}\right)$ with a HWHM of $\sim 70-80 \mathrm{~nm}$, these emission bands are inherently fixed because of the crystal structure. ${ }^{3)}$ On the other hand, if glass material without the RE cation shows white light emission comparable to the crystalline phosphor, it will be considered a novel emitting material capable of much broader emission and

\footnotetext{
Corresponding author: H. Masai; E-mail: masai_h@noncry.kuicr. kyoto-u.ac.jp
}

good formability that is quite important in the industrial manufacturing process. Since oxide glass can generally incorporate various kinds of atoms, the coordination fields of the emission center can be tuned. If the emission center was strongly affected by the coordination field, the resulting emission color is also widely tuned, which is quite different from the conventional RE-doped crystalline phosphor.

In the study, we have focused on the $\mathrm{ns}^{2}$ type emission center as an activator. Since the $n s^{2}$ type emission centers $(n \geqq 4)$, for example $\mathrm{Sn}^{2+}, \mathrm{Sb}^{3+}, \mathrm{Tl}^{+}, \mathrm{Pb}^{2+}, \mathrm{Bi}^{3+}$, and $\mathrm{Hg}^{0}$, possess an electron in the outermost shell in both the ground state $\left(\mathrm{ns}^{2}\right)$ and the excited state $\left(n s^{1} \mathrm{np}^{1}\right)$, the emission is strongly affected by the coordination field. ${ }^{1), 4)-7)}$ Considering site distribution of amorphous glass and crystal, this type of emission center is suitable for amorphous glass. Recently, the authors of this study reported the highest quantum efficiency (QE) for amorphous $\mathrm{SnO}-\mathrm{ZnO}-\mathrm{P}_{2} \mathrm{O}_{5}$ low-melting glass. ${ }^{8)}$ The oxide glass prepared by conventional melt-quenching method showed white $\sim$ blue emission that depended on the amount of $\mathrm{SnO}$. It is notable that the transparent oxide glass containing no RE cation shows high UV-excited emission that is comparable to crystal phosphor such as $\mathrm{MgWO}_{4}$; further, this was the largest efficiency of glass material without $\mathrm{RE}$ cation ever reported. The broad emission is brought about by $\mathrm{Sn}^{2+}$, which is the most conventional and harmless $\mathrm{ns}^{2}$ type center. ${ }^{9-12)}$ Moreover, the emission property of the obtained glass remains unchanged after heat treatment at forming temperature regions, which indicates that the obtained glass is suitable for low-melting glass that can be applied as the sealing material of LED. ${ }^{13), 14)}$ It is also notable that the observed emission originates from transparent amorphous material without RE cation. Since crystal phosphor or amorphous glass containing RE cation comprise most of the photoluminescent (PL) materials previously reported, the PL property of RE-free amorphous glass itself will attract considerable attention in the near future. Since the previous glass showed broad blue emission, ${ }^{8)}$ it is expected that white light emission can be attained by the addition of $\mathrm{Mn}^{2+}$ cation, similar to the $\mathrm{Sb}^{3+}, \mathrm{Mn}^{2+}$-codoped calcium halophos- 
phate. In the present study, the emission behavior was examined by changing the chemical composition of the glass. By preparation a series of $\mathrm{Sn}-\mathrm{Mn}$ co-doped glass, we have demonstrated that a white fluorescent lamp can be attained by combining UV light and RE-free amorphous glass phosphor.

\section{Experimental}

\subsection{Preparation}

The present $\mathrm{MnO}-\mathrm{SnO}-\mathrm{ZnO}-\mathrm{P}_{2} \mathrm{O}_{5}$ glass was prepared according to a conventional melt-quenching method that employs a platinum crucible of $50 \mathrm{ml}$. Batches consisting of $\mathrm{ZnO}(99.99 \%$, Kojundo chemical laboratory) and $\left(\mathrm{NH}_{4}\right)_{2} \mathrm{HPO}_{4}(99 \%$, Nacali tesque) were first heat-treated at $300^{\circ} \mathrm{C}$ for $1 \mathrm{~h}$ and $800^{\circ} \mathrm{C}$ for $3 \mathrm{~h}$ to remove $\mathrm{NH}_{3}$ and residual $\mathrm{OH}$ groups. The heat-treated glass precursor was mixed with $\mathrm{SnO}(99.5 \%$, Kojundo chemical laboratory) and $\mathrm{MnO}$ (99.9\%, Kojundo chemical laboratory), and then melted at $1100^{\circ} \mathrm{C}$ for $30 \mathrm{~min}$ at ambient atmosphere. The glass melt was quenched on a steel plate at $200^{\circ} \mathrm{C}$ and then annealed at the glass transition temperature, $T_{\mathrm{g}}$, as measured by differential thermal analysis (DTA), for $1 \mathrm{~h}$.

\subsection{Analysis}

The $T_{\mathrm{g}}$ was determined by differential thermal analysis (DTA) operated at a heating rate of $10^{\circ} \mathrm{C} / \mathrm{min}$ using TG8120 (Rigaku, Japan). The PL and PLE spectra were measured at room temperature using 850 fluorescence spectrophotometer (Hitachi, Japan). Band pass filters of PL measurement were used for the excitation $(5 \mathrm{~nm})$ and the emission $(3 \mathrm{~nm})$. The absorption spectra were measured using U3500 UV-Vis-NIR spectrometer (Hitachi, Japan).

The absolute quantum efficiency of the glass was measured using an integrating sphere C9920-02 (Hamamatsu Photonics, Japan) at room temperature. The emission decay at r.t. was measured using a Quantaurus-Tau (Hamamatsu Photonics) with $280 \mathrm{~nm}$ LED. The quantum efficiency (QE) was evaluated using normalized quantum efficiency (NQE) that was obtained by normalization of practical phosphor $\mathrm{MgWO}_{4}(3 \mathrm{~N})$ excited by the wavelength of $254 \mathrm{~nm}$. The NQE was calculated using Eq. (1):

$$
\mathrm{NQE}=P_{\mathrm{g}} \Delta E_{\mathrm{s}} / P_{\mathrm{s}} \Delta E_{\mathrm{g}},
$$

where $P_{\mathrm{g}}$ and $P_{\mathrm{s}}$ are the area intensity of glass and the standard phosphor $\mathrm{MgWO}_{4}$, respectively; $\Delta E_{\mathrm{s}}$ is the absorption of $\mathrm{MgWO}_{4}$ at $254 \mathrm{~nm}$; and $\Delta E_{\mathrm{g}}$ is the photon number absorbed by the sample, which was obtained by the difference between the area intensity of blank $E_{\mathrm{g} 0}$ and that of sample $E_{\mathrm{g} 1}$. The authors have confirmed that there was little difference between NQE value of bulk sample and that of powdered sample.

\section{Results and discussion}

Table 1 shows the chemical composition of the obtained glasses. These glasses were transparent and colorless. The $T_{\mathrm{g}} \mathrm{s}$ of these glasses were less than $440^{\circ} \mathrm{C}$, which belong to the so-called 'low-melting glass', whose manufacturing temperature is below $600^{\circ} \mathrm{C}$. Figure 1(a) shows the PL spectra of the $x \mathrm{MnO}-2.5 \mathrm{SnO}-$ $57.5 \mathrm{ZnO}-40 \mathrm{P}_{2} \mathrm{O}_{5}$ glass excited by the photon energy of $4.88 \mathrm{eV}$ $(254 \mathrm{~nm})$, which corresponds to the emission line of $\mathrm{Hg}$. This glass composition consists of $\mathrm{MnO}$ and the glass composition which showed the maximum QE in the previous report. ${ }^{8)}$ These emission spectra consist of two broad bands at 2.86 and $2.05 \mathrm{eV}$, and the former decreases with an increasing amount of $\mathrm{MnO}$, whereas the latter increases. Therefore, it can be concluded that the former correlated with the $\mathrm{Sn}^{2+}\left(5 \mathrm{~s}^{2}\right)$ emission center, while the latter correlated with the $\mathrm{Mn}^{2+}\left(3 \mathrm{~d}^{5}\right)$ center. ${ }^{15)}$ Peak
Table 1. Chemical composition of the MnO-SnO-ZnO- $\mathrm{P}_{2} \mathrm{O}_{5}$ glasses and the normalized quantum efficiency (NQE). Their chromatic coordination positions (CCPs) and colors are also shown. These glasses were excited by the photon energy of $4.88 \mathrm{eV}(254 \mathrm{~nm})$

\begin{tabular}{|c|c|c|c|c|c|c|c|}
\hline \multirow{2}{*}{$\begin{array}{c}\mathrm{MnO} \\
(\mathrm{mol} \%)\end{array}$} & \multirow{2}{*}{$\begin{array}{c}\mathrm{SnO} \\
(\mathrm{mol} \%)\end{array}$} & \multirow{2}{*}{$\begin{array}{c}\mathrm{ZnO} \\
(\mathrm{mol} \%)\end{array}$} & \multirow{2}{*}{$\begin{array}{c}\mathrm{P}_{2} \mathrm{O}_{5} \\
(\mathrm{~mol} \%)\end{array}$} & \multirow{2}{*}{$\begin{array}{c}\text { NQE } \\
( \pm 1 \%)\end{array}$} & \multicolumn{2}{|c|}{$\mathrm{CCP}$} & \multirow{2}{*}{ color } \\
\hline & & & & & $x$ & $y$ & \\
\hline 0 & 2.5 & 57.5 & 40.0 & 0.84 & 0.221 & 0.260 & \\
\hline 0.1 & 2.5 & 57.5 & 40.0 & 0.99 & 0.232 & 0.266 & \\
\hline 0.25 & 2.5 & 57.5 & 40.0 & 0.93 & 0.250 & 0.279 & \\
\hline 0.5 & 2.5 & 57.5 & 40.0 & 0.95 & 0.282 & 0.295 & \\
\hline 0.7 & 2.5 & 57.5 & 40.0 & 0.90 & 0.309 & 0.307 & \\
\hline 1.0 & 2.5 & 57.5 & 40.0 & 0.91 & 0.335 & 0.319 & \\
\hline 2.0 & 2.5 & 57.5 & 40.0 & 0.97 & 0.415 & 0.342 & \\
\hline 0.25 & 2.5 & 62.5 & 35.0 & 0.87 & 0.251 & 0.256 & \\
\hline 0.25 & 2.5 & 60.0 & 37.5 & 0.91 & 0.247 & 0.260 & \\
\hline 0.25 & 2.5 & 55.0 & 42.5 & 0.99 & 0.245 & 0.288 & \\
\hline 0.5 & 2.5 & 62.5 & 35.0 & 0.90 & 0.286 & 0.277 & \\
\hline 0.5 & 2.5 & 60.0 & 37.5 & 0.94 & 0.283 & 0.283 & \\
\hline 0.5 & 2.5 & 55.0 & 42.5 & 0.98 & 0.277 & 0.302 & \\
\hline
\end{tabular}

deconvolution revealed that these peaks showed little change in the emission band and the half width, indicating that local coordination of $\mathrm{Sn}^{2+}$ and $\mathrm{Mn}^{2+}$ was hardly affected by the concentration of $\mathrm{MnO}$. Using the ratio of these peak areas, we can estimate the correlation between the $\mathrm{Sn}^{2+}$ and $\mathrm{Mn}^{2+}$ centers. Figure 1(b) depicts the PL peak area ratio between $\mathrm{Mn}^{2+}$-derived emission and $\mathrm{Sn}^{2+}$-derived emission as a function of the nominal chemical composition ratio of $\mathrm{Mn}^{2+} / \mathrm{Sn}^{2+}$. It is suggested that $\mathrm{Sn}^{2+}$ mainly acts as an emission center at a lower $\mathrm{Mn}^{2+}$ concentration while acting as an energy donor at a higher $\mathrm{Mn}^{2+}$ concentration. Our previous paper described that about $10 \%$ of $\mathrm{Sn}^{2+}$ was oxidized into $\mathrm{Sn}^{4+}$ during the melting in the ambient atmosphere. ${ }^{8)}$ Since emission of $\mathrm{Sn}^{4+}$ is much weaker than that of $\mathrm{Sn}^{2+}$, we have discussed the effect of $\mathrm{Sn}^{2+}$ in the present paper.

Figure 2 shows PLE spectra of the $x \mathrm{MnO}-2.5 \mathrm{SnO}-57.5 \mathrm{ZnO}-$ $40 \mathrm{P}_{2} \mathrm{O}_{5}$ glasses at emission of $2.05 \mathrm{eV}$. The emission attributed to $\mathrm{Mn}^{2+}$ has several PLE bands. The main PLE band locates around $4.9 \mathrm{eV}$, which is slightly red-shifted with increasing amount of $\mathrm{Mn}^{2+}$, and small band exists at about $3 \mathrm{eV}$. The former corresponds to the photon energy of the emission line of $\mathrm{Hg}$, and the later corresponds to emission energy of $\mathrm{Sn}^{2+}$ as shown in Fig. 1. The PLE spectra indicate the energy transfer from $\mathrm{Sn}^{2+}$ and $\mathrm{Mn}^{2+}$. The excitation energy transfer, which is often explained by Dexter's theory, ${ }^{16)}$ is a key factor for practical $\mathrm{Sb}^{3+}, \mathrm{Mn}^{2+}$-doped calcium halophosphate possessing white light emission. $^{4)}$

Figure 3 shows the emission decay curves of $\mathrm{Sn}$ emission $(2.86 \mathrm{eV})$ of the $x \mathrm{MnO}-2.5 \mathrm{SnO}-57.5 \mathrm{ZnO}-40 \mathrm{P}_{2} \mathrm{O}_{5}$ glasses $(x=$ $0,0.7,2.0)$ at room temperature. The excitation light source was a 
a

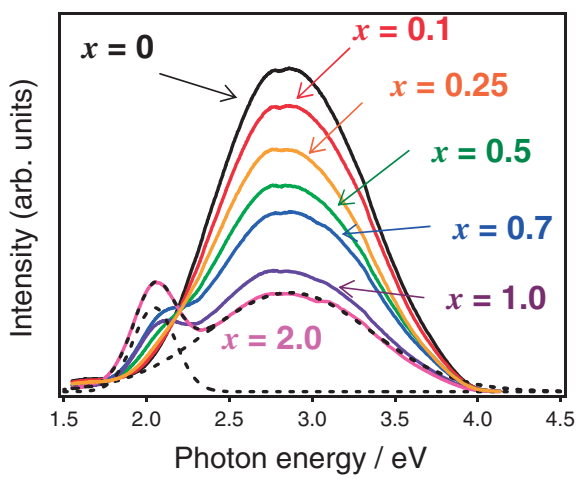

b

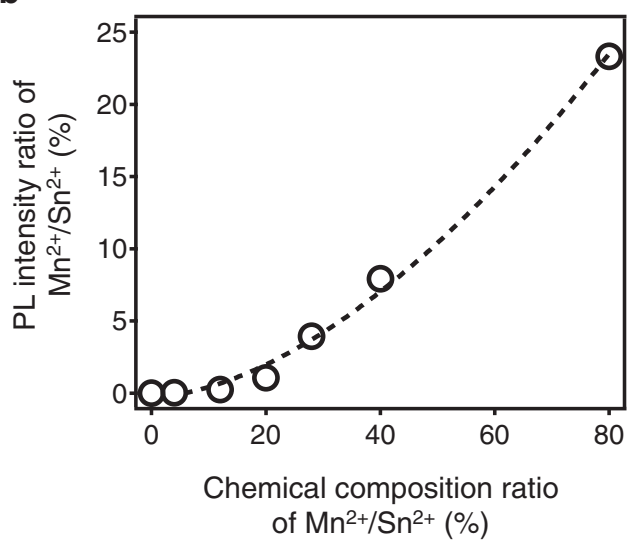

Fig. 1. PL property of the $\mathrm{MnO}-\mathrm{SnO}-\mathrm{ZnO}-\mathrm{P}_{2} \mathrm{O}_{5}$ glass. (a) Correlation between PL intensity excited by $4.88 \mathrm{eV}$ and the amount of $\mathrm{Mn}$ in the $x \mathrm{MnO}-2.5 \mathrm{SnO}-57.5 \mathrm{ZnO}-40 \mathrm{P}_{2} \mathrm{O}_{5}$ glasses. PL spectra can be deconvoluted into two bands: $2.86 \mathrm{eV}\left(\mathrm{Sn}^{2+}\right)$ and $2.05 \mathrm{eV}\left(\mathrm{Mn}^{2+}\right)$. (b) Correlation between chemical composition ratio and the PL intensity ratio of $\mathrm{Mn}^{2+} / \mathrm{Sn}^{2+}$.

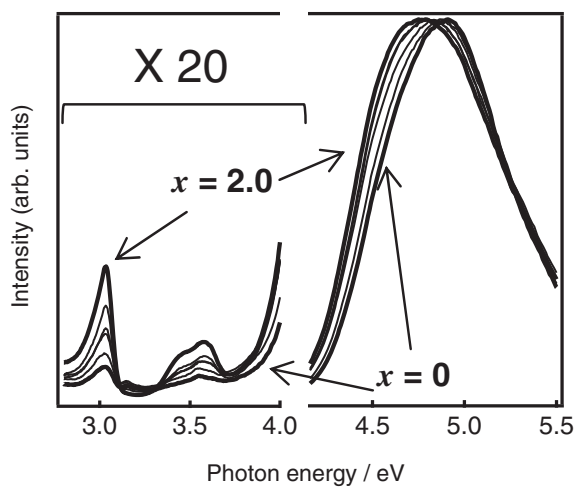

Fig. 2. PLE spectra of the $x \mathrm{MnO}-2.5 \mathrm{SnO}-57.5 \mathrm{ZnO}-40 \mathrm{P}_{2} \mathrm{O}_{5}$ glasses at emission of $2.05 \mathrm{eV}$. Intensities of PLE spectra at the region below $4.0 \mathrm{eV}$ were magnified twenty fold.

LED of $280 \mathrm{~nm}$. With increasing amount of $\mathrm{MnO}$, emission decay became short; $4.5 \mu \mathrm{s}(x=0), 3.5 \mu \mathrm{s}(x=0.7)$, and $2.1 \mu \mathrm{s}$ $(x=2.0)$. Since the shape of decay curves is changed from exponential to non-exponential, we can conclude that the $\mathrm{Sn}^{2+}$ center plays roles both in the emission center and in the energy donor to $\mathrm{Mn}^{2+}$.

Figure 4 shows a contour plot of PL intensity of $x \mathrm{MnO}-$ $2.5 \mathrm{SnO}-57.5 \mathrm{ZnO}-40 \mathrm{P}_{2} \mathrm{O}_{5}$ glass. Each figure shows the photon energy of excitation (ordinate) and emission (abscissa), and every intensity axis is shown on an identical linear scale. Broad

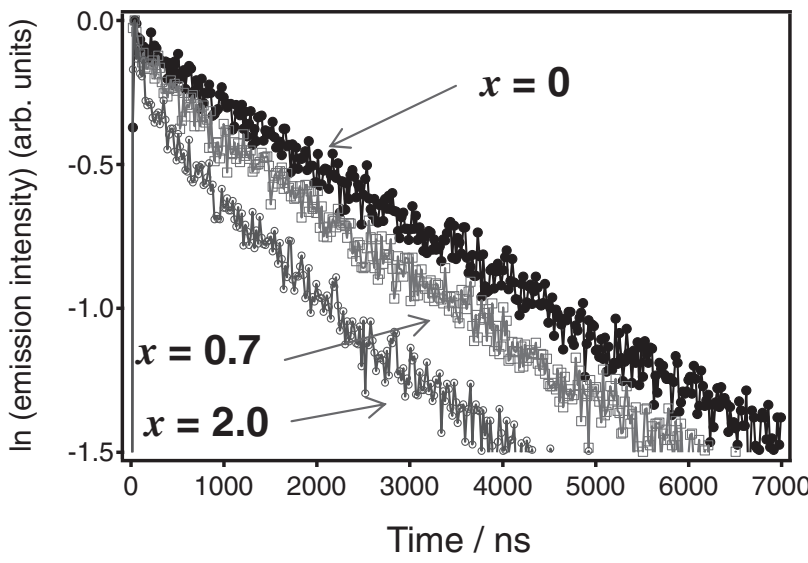

Fig. 3. Intensity decay curves of $\mathrm{Sn}$ emission $(2.86 \mathrm{eV})$ of the $x \mathrm{MnO}-$ $2.5 \mathrm{SnO}-57.5 \mathrm{ZnO}-40 \mathrm{P}_{2} \mathrm{O}_{5}$ glasses $(x=0,0.7,2.0)$. The decay curves were measured at room temperature using a $280 \mathrm{~nm}$ LED.
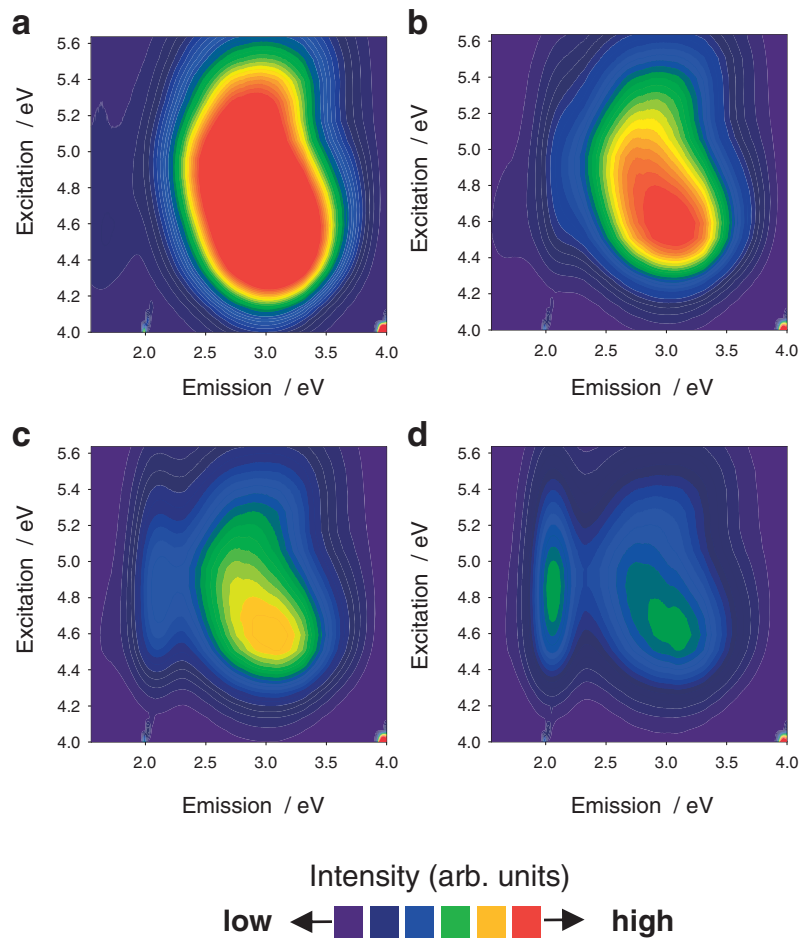

Fig. 4. Contour plot of PL intensity of the $2.5 \mathrm{SnO}-57.5 \mathrm{ZnO}-40 \mathrm{P}_{2} \mathrm{O}_{5}$ glass with different amounts of $\mathrm{MnO}$. (a) 0 , (b) 0.5 , (c) 1.0, and (d) $2.0 \mathrm{~mol} \%$. Linear scale is used for the intensity axis.

emission was observed with the excitation of UV light of $\sim 4.4-5.4 \mathrm{eV}$, and the Stokes shift was $\sim 1.0-2.0 \mathrm{eV}$. The mapping suggests that the coordination state of $\mathrm{Sn}^{2+}$ was almost unchanged in the zincphosphate glass by the addition of $\mathrm{Mn}^{2+}$, although the emission intensity was decreased by energy transfer. We have previously reported that the strongest emission peak was obtained by excitation at the photon energy of the optical band edge. ${ }^{8)}$ Comparing the absorption spectrum with the photoluminescence excitation (PLE) spectrum, the present excitation at $4.88 \mathrm{eV}$, which is higher than the optical band edge, is the most suitable position for the $\mathrm{Mn}^{2+}$ center but not for the $\mathrm{Sn}^{2+}$ center. The broad emission suggests that different emission colors can be obtained from the same glass phosphor by changing the excitation light source. 


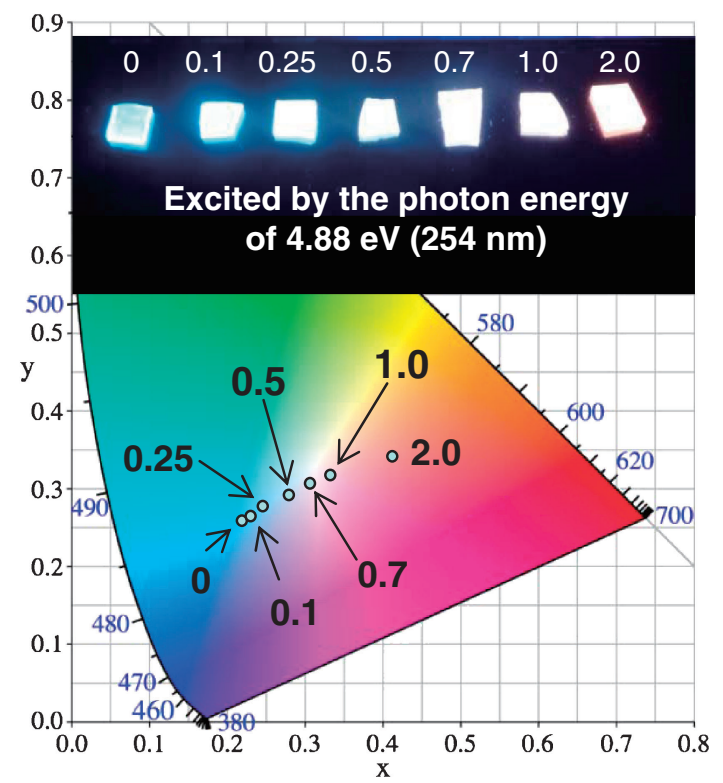

Fig. 5. Chromatic coordination mapping of the $x \mathrm{MnO}-2.5 \mathrm{SnO}-$ $57.5 \mathrm{ZnO}-40 \mathrm{P}_{2} \mathrm{O}_{5}$ glasses. Inset shows a photograph of these glasses under exposure to the wavelength of $4.88 \mathrm{eV}(254 \mathrm{~nm})$.

Figure 5 shows the photograph of $x \mathrm{MnO}-2.5 \mathrm{SnO}-57.5 \mathrm{ZnO}-$ $40 \mathrm{P}_{2} \mathrm{O}_{5}$ glass under irradiation of UV light $(4.88 \mathrm{eV}, 254 \mathrm{~nm})$ and the color coordination mapping. The NQE values and color coordination position of the samples are shown in Table 1. It is notable that these glasses show a high NQE value comparable to that of practical $\mathrm{MgWO}_{4}$, whose $\mathrm{QE}$ value was reported to be greater than $80 \%$. This value enables us to confirm the potential application of the present RE-free glass as phosphor with a high NQE. On the other hand, it is also noteworthy that the color coordination positions are continuously changed from blue to red with addition of $\mathrm{MnO}$. In particular, several glasses satisfy the white light emission condition without the RE cation. As shown in Fig. 1(a), blue color $\left(\mathrm{Sn}^{2+}\right)$ decreased with increasing amount of $\mathrm{Mn}^{2+}$. The color tuning using amount of $\mathrm{Mn}^{2+}$ was also demonstrated in the practical $\mathrm{Sb}^{3+}, \mathrm{Mn}^{2+}$-doped calcium halophosphate phosphor. However, the addition of another $\mathrm{Eu}^{2+}$-containing phosphor, such as $\mathrm{Sr}_{4} \mathrm{Al}_{14} \mathrm{O}_{25}: \mathrm{Eu}^{2+}$, is sometimes used to make up for the lack of blue color, because the $\mathrm{Sb}^{3+}, \mathrm{Mn}^{2+}$-doped calcium halophosphate shows a broad emission band around $480 \mathrm{~nm}$, which is ascribed to $\mathrm{Sb}^{3+}$ emission. Therefore, the emission ascribed to $\mathrm{Sn}^{2+}$ has an advantage over $\mathrm{Sb}^{3+}$ emission from view point of blue color without any additive $\mathrm{Eu}^{2+}$ crystallites.

Since $\mathrm{ns}^{2}$-type emission center is affected by the coordination filed, it is expected that the emission is influenced by the compositional change of the mother glass. Figure 6 shows PL and PLE spectra of the $0.5 \mathrm{MnO}-2.5 \mathrm{SnO}-y \mathrm{ZnO}-(97.5-y) \mathrm{P}_{2} \mathrm{O}_{5}$ glasses $(y=55.0$ and 62.5). The larger amount of $\mathrm{ZnO}$ the glass contained, the smaller PLE band peak and a smaller Stokes shift became. Although the observed peak shift is due to the difference of coordination field of the $\mathrm{Sn}^{2+}$ emission center, the emission band of $\mathrm{Mn}^{2+}$ is almost independent of the composition. Therefore, it clearly shows that the $\mathrm{ns}^{2}$-type $\mathrm{Sn}^{2+}$ emission center is affected by the coordination field of the glass. The socalled theoretical basicity of the glass increases with increasing amounts of $\mathrm{ZnO}$; $^{17)}$ it can thereby be said that the Stokes shift becomes smaller by increasing the optical basicity of the glass. The optical basicity of the glass was determined using the

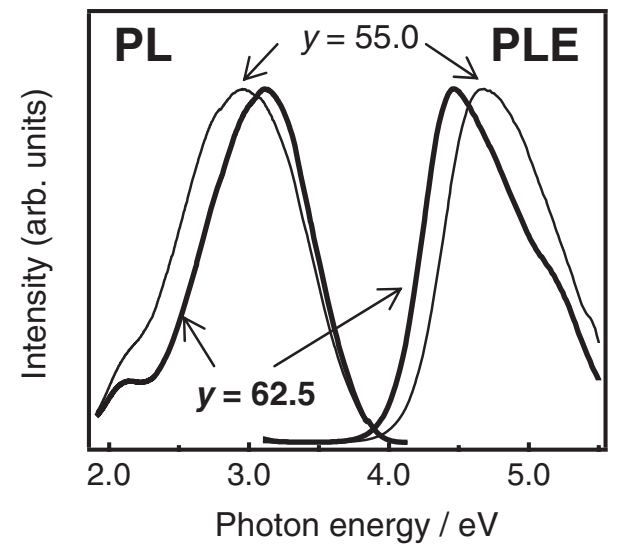

Fig. 6. $\mathrm{PL}$ and PLE spectra of the $0.5 \mathrm{MnO}-2.5 \mathrm{SnO}-y \mathrm{ZnO}-(97.5-$ y) $\mathrm{P}_{2} \mathrm{O}_{5}$ glass. $(y=55.0$ : plain, $y=62.5$ : bold).

experimentally-measured peak frequency of the ${ }^{1} \mathrm{~S}_{0} \rightarrow{ }^{3} \mathrm{P}_{1}$ transition of $\mathrm{Tl}^{+}, \mathrm{Bi}^{3+}$, and $\mathrm{Pb}^{2+}$; the $\mathrm{ns}^{2}$-type emission centers. ${ }^{18)}$ Although they reported no datum concerning $\mathrm{Sn}^{2+}$, $\mathrm{ns}^{2}$-type $\mathrm{Sn}^{2+}$ can also serve as a probe for estimation of the basicity. The observed peak shift indicates that optical basicity also increased qualitatively by addition of $\mathrm{ZnO}$. Although the amounts of emission centers $\mathrm{SnO}$ and $\mathrm{MnO}$ as well as the excitation energy were constant, the PL peak band of $\mathrm{Sn}^{2+}$ changed depending on the chemical composition of the glass. In the glass system, the PL peak attributed to $\mathrm{Sn}^{2+}$ was shifted whereas the peak attributed to $\mathrm{Mn}^{2+}$ was constant. If emission band of $\mathrm{Sn}^{2+}$ is shifted toward the UV region, the relative intensity of blue color decreases. That is the reason why the change of color listed in Table 1 is observed in several glasses that contain constant amount of $\mathrm{SnO}$ and $\mathrm{MnO}$.

From the obtained results, it is suggested that the basicity of the glass affects both the emission center and the following emission color. Since the basicity of oxide glasses is tailored by a great variety of chemical compositions, the emission color is also controlled in a wide range. Although the coordination state of activators or emission dynamics have not yet been clarified, the present results show that RE-free glass phosphor is a novel emission material that is quite different from the conventional RE-doped white light emission device. The present results indicate that the $\mathrm{Mn}$-doped $\mathrm{SnO}-\mathrm{ZnO}-\mathrm{P}_{2} \mathrm{O}_{5}$ glass will be a novel glass-based material possessing the emission property (Fig. 7). It is desirable to attain RE cation-free phosphor from view point of uneven natural resources. Since conventional organic sealant is damaged by strong and/or deep UV light, inorganic material will be required. Although the present glass shows white light emission that is similar to halo calcium phosphate crystal, there are several large differences between the two. First, for a greater number of emission centers, $\mathrm{Sn}^{2+}$ can be doped in glass. Second, various kinds of elements can be added to the glass to control the emission properties as well as to improve mechanical or thermal property. Third, monolithic material can reduce optical loss due to scattering at the interface. Moreover, transparent emission material will meet novel industrial applications. Therefore, we would like to note that such materials can be industrially applied to the sealing material for electronic devices such as LEDs because the present glass also possesses a low-melting property.

Here, we have again emphasized the advantage of combination of the present low-melting glass phosphor with a next-generation deep UV LED. If the deep UV LED is practically used, conventional organic-inorganic hybrid as well as organic 


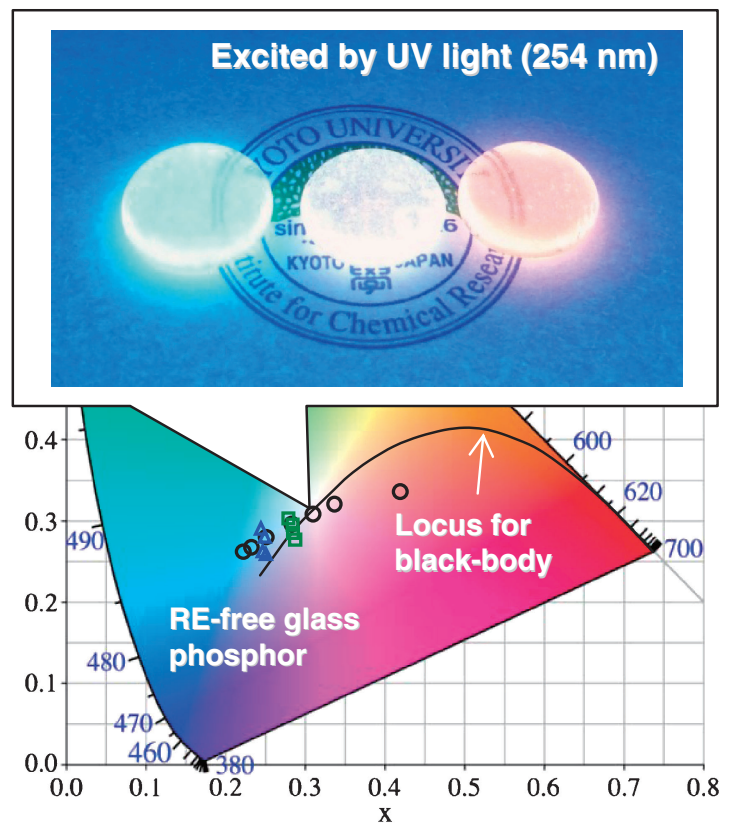

Fig. 7. Chromatic coordination mapping of the $\mathrm{SnO}-\mathrm{ZnO}-\mathrm{P}_{2} \mathrm{O}_{5}$ glasses. Black circles: $x \mathrm{MnO}-2.5 \mathrm{SnO}-57.5 \mathrm{ZnO}-40 \mathrm{P}_{2} \mathrm{O}_{5}$. Blue triangles: $0.25 \mathrm{MnO}-2.5 \mathrm{SnO}-(97.5-y) \mathrm{ZnO}-y \mathrm{P}_{2} \mathrm{O}_{5}$. Green squares: $0.5 \mathrm{MnO}-$ $2.5 \mathrm{SnO}-(97.5-z) \mathrm{ZnO}-z \mathrm{P}_{2} \mathrm{O}_{5}$. These glasses were excited by a photon energy of $4.88 \mathrm{eV}(254 \mathrm{~nm})$. The glass phosphor can attain color tuning with a wide range of color temperatures by one monolithic transparent glass. Inset shows photograph of the glass phosphors $(x=0,0.7,2.0)$ with irradiation of deep UV light $(254 \mathrm{~nm})$.

polymer cannot be applied. From this point of view, inorganic low-melting glass is the candidate for practical sealant of deep UV LED. Moreover, the visible light effectively generated at the interface between LED and the sealant glass phosphor will emit toward the outside. Since the light conversion is attained by the monolith amorphous without internal interface, the color change of device that contains the individual difference and the timedependent deterioration is inherently prevented. Although the deep-UV LED is not commercially available now, recent development of LED clearly suggests a possibility for the realization in the near future. ${ }^{19), 20)}$ The next generation white LED indicates the realization of $\mathrm{Hg}$-free white fluorescent lamps. The important point of the results is that amorphous oxide glass possessing the random structure shows high QE value comparable to conventional crystalline phosphor. Although emission of $\mathrm{Sn}^{2+}$ is explained by conventional $\mathrm{ns}^{2}$-type emission mechanism, there may exist a mechanism characteristic of amorphous material. Different from RE cation, which exhibits a high QE value because of little influence of phonons, the present $\mathrm{ns}^{2}$-type center in the glass has many uncertain points. Although we have not yet clarified the mechanism of the emission, the present RE-free glass phosphor is very fascinating material from the viewpoint of unique emission mechanisms in a random matrix.

\section{Conclusion}

We have demonstrated the UV-excited white light emission property of RE-free low-melting glasses. It is notable that high efficiency comparable to the practical crystalline phosphor is attained. The emission consisting of broad bands can be tailored by addition of another emission center such as $\mathrm{Mn}^{2+}$, or by changing the local coordination field (i.e. chemical composition of the mother glass) of $\mathrm{Sn}^{2+}$. The coexistence of high efficiency and broad emission is the unique optical property of the present glass. RE-free inorganic amorphous materials possessing emission properties by excitation of a UV LED source will be required for the novel practical optical device.

Acknowledgments This work was partially supported by Adaptable and seamless technology transfer Program through target-driven R\&D, Japan Science and Technology Agency, and the Asahi Glass Foundation. The author (H.M.) thanks Dr. A. Wakamiya (Institute for Chemical Research, Kyoto University) for allowing measurement of emission decay.

\section{References}

1) W. M. Yen, S. Shionoya and H. Yamamoto, "Phosphor handbook", 2nd edition, CRC Press, Boca Raton (2007).

2) A. Wachtel, J. Electrochem. Soc., 113, 128-134 (1966).

3) K. H. Butler and C. W. Jerome, J. Electrochem. Soc., 97, 265270 (1950).

4) R. C. Ropp and R. W. Mooney, J. Electrochem. Soc., 107, 1520 (1960).

5) T. S. Davis, E. R. Kreidler, J. A. Parodi and T. F. Soules, J. Lumin., 4, 48-62 (1971).

6) M. Leskelä, T. Koskentalo and G. Blasse, J. Solid State Chem., 59, 272-279 (1985).

7) R. H. Clapp and R. J. Ginther, J. Opt. Soc. Am., 37, 356-362 (1947).

8) H. Masai, Y. Takahashi, T. Fujiwara, S. Matsumoto and T. Yoko, Appl. Phys. Express, 3, 082102 (2010).

9) L. Skuja, J. Non-Cryst. Solids, 149, 77-95 (1992).

10) T. Hayakawa, T. Enomoto and M. Nogami, Jpn. J. Appl. Phys., 45, 5078-5083 (2006).

11) T. Akai, K. Kadono, WO2007017928-A1 (08.08.2005).

12) J. G. Hooley, US 2400147 (14.03.1946).

13) S. Matsumoto, N. Nakamura, N. Wada, WO 2009/088086 (09.01.2009).

14) S. Matsumoto, Y. Osaki, N. Nakamura, WO 2008/146886 (29.05.2008).

15) K. H. Butler, J. Electrochem. Soc., 100, 250-256 (1953).

16) D. L. Dexter, J. Chem. Phys., 21, 836-850 (1953).

17) J. A. Duffy and M. D. Ingram, J. Non-Cryst. Solids, 21, 373410 (1976).

18) J. A. Duffy and M. D. Ingram, J. Am. Chem. Soc., 93, 64486454 (1971).

19) H. Hirayama, S. Fujikawa, Y. Tsukada and N. Kamada, Oyo Buturi, 80, 319-324 (2011) [in Japanese].

20) T. Oto, R. G. Banal, K. Kataoka, M. Funato and Y. Kawakami, Nat. Photonics, 4, 767-771 (2010). 